\title{
Metodologias ativas e tecnologias digitais na formação do professor de computação
}

Adão Caron Cambraia*, Leonardo Matheus Pagani Benvenutti**

\section{Resumo}

Neste texto, apresentamos um relato de experiência da disciplina Metodologia do Ensino da Computação II, desenvolvida no curso de licenciatura em Computação do Instituto Federal de Educação, Ciência e Tecnologia Farroupilha, Campus Santo Augusto. A proposta é apresentar conceitos como: projetos, ensino híbrido, salas de aula invertidas como potenciais a práticas inovadoras na licenciatura e nas escolas de educação básica. Destacamos conceitos de metodologias ativas aliadas com as tecnologias digitais e analisamos as atividades desenvolvidas na disciplina e a importância da articulação de conhecimentos tecnológicos, pedagógicos e de conteúdo para concretizar a presença de uma cultura digital na educação. Aliamos o planejamento de projetos com tecnologias como forma de estudo e envolvimento profissional na educação, o que proporciona o entendimento de que não basta a incorporação de tecnologias na educação de forma descontextualizada, sendo fundamental um planejamento coletivo na comunidade escolar.

Palavras-chave: Formação de professores. Metodologias ativas. Tecnologias digitais.

\section{Introdução}

A licenciatura em Computação (LC) é um curso relativamente novo, pois, conforme a base de dados fornecida pelo Instituto Nacional de Estudos e Pesquisas Anísio Teixeira (Inep), apenas 3,81\% dos cursos de computação existentes no cenário brasileiro são licenciaturas (SOCIEDADE BRASILEIRA DE COMPUTAÇÃO, 2015). O primeiro curso de LC no Brasil foi criado em 1997, na Região Centro-Oeste. Conforme a Sociedade Brasileira de Computação (SBC) (2015), a LC alcançou um total de 103 cursos no Brasil, em 2015, quantitativo que demonstra uma crescente relevância nessa formação, dada a expansão dos recursos computacionais nas interações sociais nas últimas décadas, tanto no trabalho como na cultura.

\footnotetext{
Professor da licenciatura em Computação do Instituto Federal de Educação, Ciência e Tecnologia Farroupilha (Iffar). E-mail: adao.cambraia@iffarroupilha.edu.br

** Técnico administrativo em Educação e mestrando em Educação no Iffar. E-mail: leonardo.benvenutti@iffarroupilha.edu.br
} 
Como se trata de um curso de formação de professores para a educação básica, entendemos que a integração de conhecimentos das áreas de Matemática, Pedagogia, Filosofia, Sociologia, Psicologia e Computação possibilita a constituição de um docente que possa potencializar o desenvolvimento de "competências e habilidades nos eixos (Pensamento Computacional, Mundo Digital e Cultura Digital) que compõem a Computação na Educação Básica" (SBC, 2017). A integralidade do curso proporciona atuação profissional nos três eixos destacados pela SBC. Portanto, propomos uma reflexão sobre a relevância dessa formação docente a partir de um relato de experiência na disciplina Metodologia do Ensino da Computação II (MEC II), desenvolvida no $5^{\mathbf{o}}$ semestre da LC, ${ }^{1}$ no que tange ao desenvolvimento de alternativas de ensinar e aprender na cultura digital.

Os hábitos e costumes da cultura digital

[...] trazem efeitos e impactos à sociedade. Do mesmo modo, a sua negação causa impactos, pois o mundo ao redor das pessoas se adapta à evolução da máquina e do mundo virtual, não deixando de afetar as formas de relações coletivas (SBC, 2017, p. 6).

Nesse sentido, a escola, inicialmente, incorporou a cultura digital por meio dos laboratórios de informática. Hoje, a incorporação de tecnologias digitais de informação e comunicação (Tdics) na educação não depende exclusivamente dos laboratórios, pois as tecnologias assumiram outras "vestimentas", passando a permear a vida das pessoas (notebooks, celulares e diversos outros dispositivos) (VEEN; VRAKKING, 2009), possibilitando que os grupos sociais com adequadas condições tragam seus equipamentos para o espaço da sala de aula. ${ }^{2}$

Essa realidade traz a necessidade de pensar em formas de mediação por meio dessas tecnologias na educação. Com isso, procuramos perceber que são múltiplos os espaços de atuação do professor com as tecnologias digitais, como salas de aula multifuncionais e ambientes maker. Salas de aula multifuncionais são organizadas com as tecnologias e permitem uma interação aberta com o mundo, utilizando os recursos disponíveis, como celulares. Nos ambientes maker, também conhecidos como FabLab (fabrication laboratory), que são, basicamente, espaços de construção de conhecimento por meio de projetos, desenvolvemos a cultura do aprender por intermédio de projetos integradores. Na disciplina MEC II, desenvolvemos oficinas de Tdics na educação, com o objetivo de que os licenciandos aprendam a desenvolver projetos integradores, conhecendo tecnologias e pensando em como utilizá-las na educação, promovendo uma aliança entre educação e informática. Esses espaços permitem incorporar inovações na educação, como design thinking, ${ }^{3}$ gamificação, ${ }^{4}$ blended learning ${ }^{5}$ e flipped classroom. ${ }^{6}$ 
Sendo assim, este texto visa analisar o processo formativo desencadeado na disciplina MEC II, que tem o objetivo de estudar metodologias para incorporação de tecnologias no ensino da computação na educação básica (INSTITUTO FEDERAL DE EDUCAÇÃO, CIÊNCIA E TECNOLOGIA FARROUPILHA, 2014), proporcionando um melhor entendimento, tanto da comunidade acadêmica quanto da escolar, sobre o papel da LC na escola, buscando identificar algumas características da profissão. Para isso, na disciplina MEC II, estudam-se diversas tecnologias - metodologias já elencadas - e conceitos que possibilitam repensar os processos de ensinar e aprender na cultura digital. Apresentamos conceitos de metodologias ativas e tecnologias digitais na educação, desencadeando um processo de participação intensa dos alunos na construção do conhecimento. Ao vivenciar a importância desse processo na relação professor/aluno, acreditamos que há potencialidade de inovação nas práticas pedagógicas, nos saberes e fazeres da profissão.

\section{Relato de experiência da disciplina Metodologia do Ensino da Computação II}

Este tópico está dividido em três partes: ${ }^{7}$ a primeira apresenta conceitos teóricos da disciplina (metodologias ativas
- projetos de aprendizagem, de trabalho, integradores, interdisciplinares, design thinking, gamificação, ensino híbrido, sala de aula invertida), concretizando-os com a turma de MEC II; a segunda parte traz o encaminhamento da pesquisa sobre tecnologias digitais; e a terceira apresenta a construção de projetos com o uso das metodologias e tecnologias estudadas.

Na primeira parte, para contextualizar e problematizar, desenvolvemos uma aula expositiva e dialogada, visando compreender o conceito de metodologia. Para isso, foi utilizado o texto "Metodologia do ensino: diferentes concepções" (MANFREDI, 1993). Após a leitura e a discussão, foi utilizado o ambiente Padlet para construir um mural eletrônico do conhecimento em questão. Os licenciandos assinalaram dois destaques, duas dúvidas e dois questionamentos sobre o texto apresentado e escreveram suas concepções sobre o conceito de metodologia. Foi um momento de entender a complexidade do fazer docente, entender que não existe uma metodologia, e sim metodologias contextualizadas, que o ensinar e o aprender são processos em permanente (re)construção.

A aprendizagem permanente é uma necessidade, pois as informações e os conhecimentos estão em intenso movimento. Seu ciclo de renovação é cada vez mais curto, proporcionando que o volume de informações duplique a cada renovação. Conforme Lévy: 
Até a segunda metade do século XX, uma pessoa [...] transmitia geralmente seu saber, quase inalterado, a seus filhos ou a aprendizes. Hoje, esse esquema está em grande parte obsoleto. As pessoas não apenas são levadas a mudar várias vezes de profissão em sua vida, como também, no interior da mesma "profissão", os conhecimentos têm um ciclo de renovação cada vez mais curto (três anos, ou até menos, em informática, por exemplo) (1996, p. 54).

Dessa forma, exige-se que as pessoas aprendam e passem a construir conhecimentos ao longo da vida (CLAXTON, 2005). Os professores e os alunos têm que ser não apenas consumidores de conhecimentos que os outros produzem, mas se tornarem protagonistas no processo de construção do conhecimento, o que requer posturas de reflexão, inovação, pesquisa, aprendizado e cooperação ética entre as pessoas. Não se trata mais de somente transmitir informações, mas de habilitar o estudante a selecioná-las, transformando-as em conhecimento, e mobilizá-lo a serviço de pessoas e seus projetos de vida (MACHADO, 2000).

Machado (2000) faz uma distinção entre dados, informação, conhecimento e inteligência para entendermos o papel docente na contemporaneidade. $\mathrm{O}$ autor conceitua e distingue dados e informação por meio de um exemplo: poderíamos criar um banco de dados com informação referente a todas as pessoas do mundo (nome, cidade, endereço, profissão, contato, etc.). Esses dados não representam nada para a maioria das pessoas. Até que alguém, em uma viagem a Paris, necessite, por exemplo, de um médico. Assim, acessa a base de dados e extrai a informação que deseja. Ou seja, convertemos um dado sem sentido em uma informação. O mesmo ocorre com o conhecimento, não basta o simples acúmulo de informações. A construção do conhecimento:

Pressupõe o estabelecimento de uma densa rede de interconexões entre as informações, uma apreensão do contexto, uma compreensão do significado, uma visão articulada de todo cenário de informações, que se torna passível de uma mobilização para a ação (MACHADO, 2000, p. 78).

A articulação entre conhecimento e inteligência ocorre por meio da mesma relação que converte dados em informação, ou seja, o "conhecimento não pode ser considerado um fim em si mesmo" (MACHADO, 2000, p. 79). Conforme Machado (2000), acima do conhecimento estão as pessoas, com sua inteligência, seus desejos e seus projetos. Segundo Guy Claxton (2005), inteligência é aliar as ferramentas internas com as externas para se movimentar no mar de informações e não ficar à deriva.

Conforme Demo (2006), ensinar é fazer com que o aluno aprenda a questionar o que lhe é ensinado, para aprender a aprender. Isso demonstra que precisamos não somente achar respostas, mas questionar, formular problemas. Não se trata apenas de o professor formular 
questões para os alunos responderem, trata-se de eles próprios formularem suas questões, tendo-se o professor e os alunos como mediadores e problematizadores. É interessante ressaltar que, quando o próprio sujeito problematiza sua realidade, esta se torna mais significativa, já que parte de seu conhecimento anterior. Em outras palavras, o papel do professor, mais do que "dar matérias" e/ou "transmitir informações”, é despertar o interesse dos alunos, tornar interessante o que é necessário. Não ocorre construção do conhecimento quando tudo está bem ou quando não possuímos problemas. Então, como provocar um ciclo virtuoso de problematizações para potencializar o ensinar e o aprender na cultura digital?

$\mathrm{Na}$ cultura digital, aprende-se em diferentes lugares, em diferentes tempos, interagindo com diferentes pessoas. Serres (2000) descreve uma situação que se passa na França: um funcionário de alto escalão do governo, ao fazer uma palestra em uma universidade, anuncia que contratará um estagiário para atuar num ministério. Alguns alunos se interessam e começam a estudar pela internet tudo que encontram sobre a vaga. Meses depois, um deles é selecionado. Os funcionários mais antigos interagem com o neófito e percebem que ele sabe mais sobre o setor do que eles próprios. Serres destaca que essa é uma característica nova da sociedade imersa na cultura digital, aprendemos permanentemente.
Além disso, o exercício frequente da autoria (escrita hipertextual e multimídia) é uma maneira de possibilitar esse autoquestionar e, ainda, permite uma melhor fundamentação dos argumentos e conhecimentos em reconstrução. A utilização das Tdics na escola, ao contrário da maioria dos meios de comunicação de massa, proporciona esse exercício de autoria, o aluno e o professor podem se tornar autores, impulsionando a criação coletiva e a interação mútua (PRIMO, 2003). Não se trata de inserir tecnologias para fazer mais do mesmo. As Tdics potencializam a constituição de espaços de protagonismo e formação permanente, desenvolvendo processos de aprender a aprender, de reconstrução do conhecimento pela pesquisa de forma colaborativa, vinculando sistemicamente a aprendizagem individual com a coletiva. Tratam-se de novos papéis: "ao novo papel do professor equivale a construção de um novo papel para o aluno" (ALONSO et al., 2014, p. 162).

A comunicação ocorre em diversos formatos, por meio de vídeos, podcasts, textos, imagens. A multimídia povoa os circuitos comunicacionais, potencializando processos mais interativos. É um movimento de superação de um modelo que propõe uma verdade única e libera os polos de emissão em que professores e alunos em interlocução aprendem juntos, problematizam e reconstroem o conhecimento. Sendo assim, as Tdics 
têm um papel fundamental na construção de uma sala de aula mais interativa (SILVA, 2001) e de uma nova cultura de aprendizagem (POZO, 2002).

Além de potencializar a reflexão e a reconstrução de argumentos, a autoria no ciberespaço (por meio de tecnologias, como a web 2.0) possibilita a colaboração, a comunicação e a avaliação dos conhecimentos em rede, permitindo o recebimento de críticas, sugestões e complementação de ideias, levando-nos novamente à reflexão sobre os conceitos elaborados. Assim, de acordo com Moraes e Valderez (2002), o professor e o aluno participam do ciclo dialético essencial ao educar pela pesquisa, composto pelos elementos: questionamento, construção de argumentos, comunicação e avaliação.

Retomando as atividades da disciplina MEC II, o professor, enquanto organizador e problematizador do conhecimento (GADOTTI, 2011; DEMO, 2006), desenvolveu materiais didáticos digitais com diferentes temáticas, em forma de hipertextos gravados via Google Docs e compartilhados com os grupos. Cada material apresentando uma variedade de hiperlinks, que permitia o desenvolvimento de estudos de acordo com o interesse de cada aluno. O material didático possibilitou aprofundar as temáticas, pois a hipertextualidade possibilitava-lhes percorrer diferentes caminhos. Cada hiperlink abria novos hiperlinks, nós de comunicação, assim, o estudo nunca se esgotava. Os sites abriram inúmeras trajetórias de estudos sobre as temáticas, possibilitando aos futuros professores o entendimento das novas dinâmicas de ensinar e aprender na cultura digital, em que o processo de autoria é construído pela escrita e pelas inúmeras possibilidades de leituras hipertextuais (LÉVY, 1999). Essa atividade possibilitou entender uma característica do professor de computação, já destacada por Eder (2001): a multilocalidade - em que somos desafiados a aprender o tempo todo e em todos os lugares.

No início de cada aula, era realizada uma problematização e a apresentação das temáticas sugeridas. Posteriormente, cada grupo escolhia a temática de interesse. Nesse momento, as temáticas para estudos coletivos foram: 1) entender o cenário - a relação dos jovens com as tecnologias; 2) design thinking na educação; 3) espaços alternativos imersos em tecnologias (ambiente maker e FabLab); 4) ensino híbrido e sala de aula invertida; 5) metodologias ativas; 6) inovações na educação. Os grupos organizaram apresentações e a socialização dos resultados foi realizada em um seminário integrador (SI).

Foi utilizado o ambiente $E d m o d o^{8}$ para compartilhar o material didático hipertextual para estudo coletivo. Aideia inicial foi a de que os alunos elaborassem o estudo extraclasse e trouxessem para a sala de aula sistematizações com apro- 
fundamentos para serem discutidos por meio de SI, utilizando o conceito de sala de aula invertida, porém, a experiência não foi satisfatória. Os alunos relataram uma série de obstáculos, como a falta de tempo em casa (a grande maioria são trabalhadores) e o fato de os grupos não conseguirem se encontrar, entre outros. Assim, optamos por introduzir a sala de aula invertida na turma ao longo do curso, no espaço-tempo disciplinar. Desse modo, os estudos orientados foram realizados em determinadas aulas e a apresentação da sistematização em outras.

A disciplina MEC II utilizou o Edmodo como um espaço de discussões, compartilhamento e repositório de materiais, como vídeos, apresentações, textos e as atividades desenvolvidas pelos grupos, como forma de proporcionar interação entre os colegas para estudarem as demais temáticas. Eles compartilharam também apresentações desenvolvidas na plataforma Prezi. ${ }^{9}$ Cada grupo foi desafiado a formular questionamentos e a postar no ambiente $E d m o d o$, o que proporcionou uma intensa interatividade no ambiente virtual de aprendizagem (AVA) sobre metodologias ativas na educação.

José Moran (2017) destaca algumas metodologias que envolvem atividades cada vez mais complexas, em que os alunos tomam decisões e negociam os resultados, tais como: aprendizagem baseada em problemas; aprendizagem baseada em projetos; projetos dentro de cada dis- ciplina; projetos integradores; projetos transdisciplinares. Pela pedagogia de projetos, relacionamos o que Machado (2000) denomina de intradisciplinar e transdisciplinar, o que possibilita a construção de significados dos conceitos disciplinares com o mundo da vida. Os projetos são marcados pela intencionalidade de que o aluno seja protagonista na construção do conhecimento e que, mediante a utilização de diferentes procedimentos, localize, selecione, analise, interprete e sistematize as informações para mobilizar conhecimentos a serviço das pessoas (CAMBRAIA; MOURA; SILVA, 2017), construindo diferentes percursos de aprendizagem.

Na segunda parte, compartilhamos uma diversidade de tecnologias digitais. Socializamos endereços de sites, softwares e materiais de apoio, com o intuito de que cada aluno desenvolvesse sua pesquisa e integrasse tecnologias com as metodologias estudadas. Nesse ponto, usamos o software Symbaloo ${ }^{10}$ para compartilhar diferentes endereços de softwares educacionais. A intenção foi a de que os grupos identificassem tecnologias que potencializassem atividades com metodologias ativas. Além dos endereços de tecnologias disponibilizadas pelo Symbaloo, os grupos foram motivados a compartilhar outras tecnologias descobertas no processo, com o intuito de que percebessem a multiplicidade de recursos disponíveis na internet. 
Posteriormente, em duplas, os alunos elencaram três tecnologias e desenvolveram oficinas para o restante da turma. Com isso, aprendemos uma diversidade de novas aplicações e possíveis relações com a educação, dentre as quais destacam-se algumas oficinas desenvolvidas pelos alunos: criação e edição de vídeos para o YouTube; acesso e disponibilização de planos de aula no portal do professor; uso de Pinterest, Duolingo e Khan Academy; criação de mapas conceituais com o Cooglet. Como a proposta foi potencializar a atuação ativa dos alunos na produção do conhecimento, entendemos que as Tdics têm um papel fundamental conjuntamente com a metodologia de projetos, pois possibilitam uma gama de recursos que intensifica a mediação, a interação e a articulação entre os diferentes envolvidos no processo educacional.

As metodologias ativas permitem aprofundar as discussões com novas leituras e socializar as diferentes compreensões construídas, além de proporcionarem a compreensão da importância da contextualização e do planejamento de projetos para cada turma, relacionando os conceitos de cada disciplina com a realidade da comunidade. Não se trata de excluir as disciplinas escolares em nome do desenvolvimento de projetos, mas, sim, de reforçá-las de modo integralizado. Dessa forma, a escola desempenha um papel de aprofundamento do conhecimento e a contextualização e a aproximação com a realidade, uma relação paradigmática complexa entre disciplinar e interdisciplinar e/ou transdisciplinar (SILVA, 2016).

Na terceira parte da disciplina MEC II, a turma foi desafiada e interligar os dois blocos (tecnologias com metodologias ativas) e pensar projetos integradores para serem desenvolvidos nas escolas. A metodologia de projetos é discutida desde o século XIX, por autores como Dewey, mas, recentemente, foi assumida - por autores como Hernández e Ventura (1998) - como possibilidade de uma educação contextualizada, que atribua mais sentido e significados à aprendizagem. Assim, planejamento, acompanhamento e avaliação de projetos proporcionam aos professores a oportunidade de repensar ações, provocando um movimento reflexivo de recriação da prática curricular.

Com o intuito de provocar esse movimento reflexivo, propomos aos alunos pensar em projetos integradores para serem desenvolvidos nas escolas. Os trabalhos foram compartilhados por meio de uma apresentação coletiva (cada aluno propôs um projeto). Assim, o curso de LC possibilita ao docente a criação de metodologias ativas para o ensino da computação e a articulação das Tdics com outras áreas, possibilitando a compreensão de que o curso é multifocal e multifacetado (EDER, 2001), o que exige uma formação interdisciplinar. 
Um dos grupos se propôs a pensar a gamificação para o ensino de programação, recurso considerável para um professor de Computação. Outros grupos articularam metodologias e tecnologias com uma terceira disciplina, a língua estrangeira. Por isso, entendemos que o professor de computação também atua como articulador de projetos integradores na escola (conhecedor de tecnologias e educação), potencializando usos inovadores. Os projetos propostos foram compartilhados no Google Apresentação, e cada aluno teve oportunidade de comentar o projeto do colega e sugerir modificações.

Outro aspecto desenvolvido nas aulas da disciplina MEC II foi entender o TPACK (Technological Pedagogical Content Knowledge). De acordo com Koehler e Mishra (2009), a formação de professores requer uma integração de conhecimentos em tecnologia, pedagogia e conteúdo. Os autores apresentam sete tipos de "conhecimentos" derivados dos três grandes eixos (conteúdo - eixo 1; pedagógico - eixo 2; tecnológico - eixo 3) e três interações entre esses eixos (conhecimento tecnológico-pedagógico; conhecimento tecnológico do conteúdo; conhecimento pedagógico do conteúdo) e o sétimo tipo de conhecimento - que surge do contexto específico em que as práticas acontecem. A habilidade de realizar a interação entre os três componentes (conhecimento de tecnologia, pedagogia e conteúdo) é importante para que os professores consigam integrar as Tdics de forma eficaz em suas práticas docentes e, consequentemente, proporcionem que a cultura digital esteja presente na escola.

Diante disso, não basta incorporar as Tdics em sala de aula, sem articular com a educação e os conhecimentos dos conteúdos. Na LC, elaboramos relações entre conhecimento pedagógico e tecnológico. As demais relações foram lançadas como desafios aos futuros professores, pois exigem uma interação com a escola para uma contextualização. Essa reflexão ficou em aberto. Sugerimos uma articulação com a prática como componente curricular e/ou com estágios curriculares supervisionados, disciplinas do curso, para suprir essa demanda. Como a maioria dos contatos com as escolas (estágios, práticas como componente curricular e programa institucional de bolsa de iniciação à docência) são efetivados e executados por uma interação do licenciando com professores de outras áreas, no sentido de potencializar o desenvolvimento de atividades das Tdics como ferramentas cognitivas (JONASSEN, 2007), tanto a interação com a escola como uma pesquisa colaborativa são necessárias para que a tecnologia não seja apenas injetada na escola, mas que sejam criados sentidos para a incorporação das Tdics na educação em consonância com as necessidades de cada comunidade escolar. 
O esboço de projeto serviu como ponto de partida para que os alunos escrevessem textos coletivos, valorizando a escrita colaborativa. Os licenciandos criaram um texto no Google Docs e compartilharam com a turma. Cada aluno comentou os textos dos colegas, o que proporcionou uma escrita reflexiva e autônoma do projeto. De acordo com Marques (2001, p. 26), escrevemos para pensar, pois o escrever serve como "provocação ao pensar, como suave deslizar da reflexão, como a busca do aprender, princípio da investigação". Ao desenvolver essas atividades com os alunos, percebemos que há dificuldades de escrita e que o professor desempenha, nesse caso, o papel de um facilitador/ problematizador do processo reflexivo. Essa produção perpassou por inúmeras escritas e reescritas durante 0 semestre, enquanto o professor atuou como um amigo crítico (CARR; KEMMIS, 1988), mostrando novos horizontes e problematizando o fazer docente.

No ato de escrever, também nos colocamos em interlocução com um primeiro leitor do texto, um leitor virtual, percebendo, assim, "a indefectível presença do virtual leitor no ato mesmo de escrever. Presença à distância, oculta, tácita e, por isso mesmo, desafiante, perturbadora, angustiante" (MARQUES, 2001, p. 38), que nos coloca em um processo de escrever e reescrever, provocando tensões que constituem o pensamento complexo. Como os materiais produzidos pelos alunos são disponibilizados por meio da rede, outras pessoas têm acesso, o que proporciona novos processos de autoria e construção coletiva do conhecimento. A autoria hipertextual por meio das ferramentas cognitivas possibilita uma religação dos saberes (MORIN, 2013) e o desenvolvimento do pensamento complexo. No final do semestre, foram distribuídos os textos para que os demais professores do curso pudessem interferir e reescrever, sugerindo novos enfoques. Esses artigos farão parte de um livro sobre metodologias ativas, valorizando a produção intelectual dos futuros professores.

A avaliação da disciplina foi qualitativa e processual, não ocorreu com provas. Além dos diversos trabalhos construídos, foram considerados o texto escrito e o mapa conceitual em que os alunos foram desafiados a destacar conhecimentos significativos construídos na disciplina MEC II. Ao propor uma avaliação por meio de mapas conceituais, foi possível entender a produção personalizada de conhecimentos, em que cada aluno produziu uma trajetória diferente. Utilizar o mapa conceitual para a avaliação das trajetórias construídas pelos estudantes possibilitou a vivência de novas formas de construção do conhecimento e permitiu repensar o processo de avaliação. $\mathrm{Na}$ apresentação dos mapas conceituais, percebemos a trajetória construída pelo aluno. 
De acordo com Morin (2006), mais vale uma cabeça bem-feita do que uma cabeça cheia, ou seja, não se trata de avaliar para detectar a quantidade de informações que o aluno armazenou, mas fazer com que o aluno possa demonstrar os diferentes entendimentos construídos e utilizar esses saberes em diferentes situações da vida.

\section{Considerações finais}

A disciplina MEC II proporcionou o desenvolvimento de um trabalho com metodologias ativas e tecnologias digitais, proporcionando aos futuros professores construir diferentes trajetórias na elaboração do conhecimento e vivenciar essas inovações para proporcionar transformações no espaço da escola, permitindo, por meio da socialização dos projetos integradores, a compreensão da profissão como multifocal e multifacetada: como um professor que atua no ensino da computação e como um professor articulador dos diferentes campos com intuito de criar projetos com tecnologias digitais.

A articulação de Tdics e metodologias ativas ajuda a entender a complexidade existente na educação. A aliança entre educação e computação é mais do que apenas desenvolver capacitações para o uso de tecnologias na educação, envolve pensar e articular metodologias e tecnologias que proporcionem uma parti- cipação ativa dos sujeitos envolvidos no processo educacional, transformando as formas de ensinar a aprender na cultura digital. Ao contextualizar o projeto e as Tdics, proporciona-se uma dinâmica de produção do conhecimento significativo, fazendo com que os alunos se vejam como sujeitos ativos no processo de construção do conhecimento. $\mathrm{O}$ ensino híbrido e a sala de aula invertida proporcionam atividades de discussão com propriedade, de forma mais aprofundada.

Para que a inovação se concretize na escola, a pesquisa colaborativa envolvendo agentes articuladores (professores formadores, licenciandos, professores de educação básica) precisa pautar o processo formativo docente, integrando Tdics e projetos integradores. Para isso, é necessário o permanente diálogo com os demais docentes, pois isso proporciona atividades contextualizadas com a cultura da comunidade. Assim, sugerimos a criação de momentos formativos nas escolas, com a articulação de conhecimentos pedagógicos, tecnológicos e de conteúdo, proporcionando a identificação das necessidades na escola.

Com este relato, percebemos que a LC compreende um projeto educativo aberto ao diálogo em termos intrínsecos, ou seja, dos participantes do ato educativo, institucionalizado, bem como extrínsecos, de percepção contextual e global, demandado pelo momento que vivenciamos. 


\section{Active methodologies and digital technologies in computing teacher's formation}

\section{Abstract}

This text presents an experience report of the discipline of Methodology of Teaching of Computing II developed in the Computing Teacher's Formation Course from Instituto Federal de Educação, Ciência e Tecnologia Farroupilha, Campus Santo Augusto. The purpose was to present concepts such as: projects, hybrid teaching, flipped classroom as potential to innovative practices in teacher formation course and in the Basic Education schools. In the text we present concepts of active methodologies allied with digital technologies. We analyze the activities developed in the discipline and the meaning in the articulation of technological knowledge, pedagogical and content in the sense to realize the presence of a digital culture in education. We combine the planning of projects with technologies as a way to study and professional engagement in education, which provides the understanding that is not enough embedding technologies in education in a decontextualized way, being fundamental a collective planning in the school community.

Keywords: Teacher's formation. Active methodologies. Digital technologies.

\section{Notas}

1 Agradecimento à Fapergs pelo fomento a esta pesquisa, conforme Edital n.․ 01/2017 - ARD.

2 Esse fenômeno, conhecido como Bring Your Own Device, já ocorre na maioria das escolas brasileiras e é domesticado pelas pedagogias tradicionais, que proíbem qualquer manifestação da cultura digital na escola.
3 Metodologia de abordagem colaborativa para 0 desenvolvimento de projetos complexos.

4 Gamificação não significa a utilização de jogos na educação, mas a incorporação de estratégias de gamificação em portais de ensino e aprendizagem, tais como inteligência artificial, desafios, metas, bônus e rankeamento.

5 Híbrido, ensino misturado; em outras palavras, misturar aspectos positivos do ensino tradicional com recursos do ensino on-line.

6 A ideia da sala de aula invertida foi difundida com o desenvolvimento e a utilização de vídeos na educação, o que possibilita que os alunos assistam à apresentação dos conceitos em casa e, na aula, façam exercícios e resolvam dúvidas. Entendemos que a sala de aula invertida é uma forma de proporcionar, no espaço da escola, o aprofundamento do conhecimento.

7 Essa divisão foi realizada também na disciplina, e trazê-la para o texto objetiva melhor organizá-lo. Cada parte não representa uma aula, e sim mais de uma, sendo que elas foram inter-relacionadas no decorrer das discussões.

8 Rede social de aprendizagem que no texto é denominada de ambiente virtual de aprendizagem (AVA), mesmo sem contemplar todas as características de um AVA.

9 Plataforma para montagem de apresentações hipertextuais.

10 Plataforma para organização e socialização hipertextual.

\section{Referências}

ALONSO, K. M. et al. Aprender e ensinar em tempos de cultura digital. Revista de Educação a Distância: em Rede, Porto Alegre, v. 1, n. 1, p. 152-168, 2014.

CAMBRAIA, A. C.; MOURA, S. P.; SILVA, H. A. Educar pela pesquisa: construção dialógica do projeto integrador na Educação Básica. Curitiba: CRV, 2017. (Coleção Educação, Espaço construído e Tecnologias: reflexões, desafios e perspectivas).

CARR, W.; KEMMIS, S. Teoria crítica de la enseñanza: investigación-acción en la formación 
del profesorado. Barcelona: Martinez Roca, 1988.

CLAXTON, G. O desafio de aprender ao longo da vida. Tradução de Magda Lopes. Porto Alegre: Artmed, 2005.

DEMO, Pedro. Formação permanente e tecnologias educacionais. Petrópolis, RJ: Vozes, 2006.

EDER, O. A formação do profissional de informática com vistas ao exercício pedagógico da profissão. Ijuí: Editora Unijuí, 2001.

HERNÁNDEZ, F.; VENTURA, M. A organização do currículo por projetos de trabalho: o conhecimento é um caleidoscópio. Tradução de Jussara Hauber Rodrigues. 5. ed. Porto Alegre: Artes Médicas, 1998.

GADOTTI, Moacir. Boniteza de um sonho: ensinar-e-aprender com sentido. 2. ed. São Paulo: Editora e Livraria Instituto Paulo Freire, 2011.

INSTITUTO FEDERAL DE EDUCAÇÃO, CIÊNCIA E TECNOLOGIA FARROUPILHA. Projeto Pedagógico do Curso de Licenciatura em Computação. Santo Augusto: Instituto Federal Farroupilha, 2014. Disponível em: <http:// www.sa.IF Farroupilha.edu.br/>. Acesso em: 29 mar. 2014.

JONASSEN, David H. Computadores, ferramentas cognitivas: desenvolver o pensamento crítico nas escolas. Tradução de Ana Rosa Gonçalves, Sandra Fradão e Maria Francisca Soares. Porto: Porto Editora, 2007.

KOEHLER, M. J.; MISHRA, P. What is technological pedagogical content knowledge? Contemporary Issues in Technology and Teacher Education, Michigan, v. 9, n. 1, p. 60-70, 2009. Disponível em: <https://citejournal.s3.amazonaws.com/wp-content/uploads/2016/04/v9i1general1.pdf>. Acesso em: 04 abr. 2017.

LÉVY, Pierre. Cibercultura. Tradução de Carlos Irineu da Costa. São Paulo: Editora 34, 1999.

O que é virtual. Tradução de Paulo Neves. São Paulo: Editora 34, 1996.

MACHADO, Nílson José. Educação: projetos e valores. São Paulo: Escrituras, 2000.
MANFREDI, Sílvia Maria. Metodologia do ensino: diferentes concepções. Campinas: F. E./ Unicamp, 1993. Disponível em: <http://www. academia.edu/download/35891464/METODOLOGIA-DO-ENSINO-diferentes-concepcoe-s. doc>. Acesso em: 10 out. 2017.

MARQUES, M. O. Escrever é preciso: o princípio da pesquisa. 4. ed. Ijuí: Unijuí, 2001.

MORAES, R.; VALDEREZ, M. R. L. (Org.). Pesquisa em sala de aula: tendências para educação em novos tempos. Porto Alegre: EDIPUCRS, 2002.

MORAN, J. Metodologias ativas para uma aprendizagem mais profunda. Educatrix Dossiê Currículo, São Paulo: Moderna, a. 7, n. 12 , p. 66-69, 2017.

MORIN, E. A cabeça bem-feita: repensar a reforma, reformar o pensamento. Tradução de Eloá Jacobina. 12. ed. Rio de Janeiro: Bertrand Brasil, 2006.

A religação dos saberes: o desafio do século XXI. Tradução de Flávia Nascimento. 11. ed. Rio de Janeiro: Bertrand Brasil, 2013.

POZO, J. I. Aprendizes e mestres: a nova cultura da aprendizagem. Tradução de Ernani Rosa. Porto Alegre: Artmed, 2002.

PRIMO, A. Interação mediada por computador: a comunicação e a educação a distância segundo uma perspectiva sistêmico-relacional. 2003. Tese (Doutorado em Informática na Educação) Programa de Pós-Graduação em Informática na Educação, Universidade Federal do Rio Grande do Sul, Porto Alegre, 2003.

SOCIEDADE BRASILEIRA DE COMPUTAÇÃO. Educação Superior em Computação Estatísticas. 2015. Disponível em: <https://bit. ly/2JcXzZG>. Acesso em: 05 jul. 2015.

Referências de Formação em Computação: Educação Básica. Versão Julho de 2017. (Aprovado pela Comissão de Educação e apresentado no CSBC 2017). Disponível em: <http:// www.sbc.org.br/noticias/10-slideshow-noticias/ 1996-referenciais-de-formacao-em-computacao-educacao-basica> . Acesso em: 18 jul. 2017. 
SERRES, Michel. Novas tecnologias e sociedade pedagógica: uma conversa com Michel Serres. Interface - Comunicação, Saúde, Educação, Botucatu, v. 4, n. 6, fev. 2000. Disponível em: $<$ http://www.scielo.br/scielo.php?script=sci_arttext\&pid=S1414-32832000000100013>. Acesso em: 28 jan. 2018 .

SILVA, Marco. Sala de aula interativa. 2. ed. Rio de Janeiro: Quartet, 2001.

SILVA, Sidinei Pithan da. Conhecimento e complexidade: notas sobre o disciplinar, o interdisciplinar e o transdisciplinar na educação. In: MARTINAZZO, C. J.; SILVA, S. P.; CASSOL, C. V. (Org.). Complexidade e educação em diálogo. Ijuí: Editora Unijuí; Frederico Westphalen: URI, 2016. p. 19-34.

VEEN, W.; VRAKKING, B. Homo Zapiens: educando na era digital. Tradução de Vinicius Figueira. Porto Alegre: Artmed, 2009. 